schizophrenic to illustrate the bleak reality of being mentally ill and homeless ( $p$ 726). ${ }^{\text {7a }}$ The experiment in which people inflicted electric shocks on subjects who were actually actors is known to all psychology students, and even journalology has an important study that depended on deception: editors had papers that they had already published resubmitted to them with the titles and addresses changed and then rejected most of them-providing evidence, the researchers argued, that editors and referees were biased against authors from provincial universities. ${ }^{8}$

The study we publish today provides further evidence of racial discrimination in British medicine. Few doctors trained overseas will be surprised by the result. Many of them believe that the immigration of overseas doctors was encouraged to support the NHS in its early days, only for the overseas doctors subsequently to be marginalised. Australia has also seen debate over whether doctors trained overseas suffer racial discrimination. ${ }^{910}$ The demonstration of discrimination at St George's Hospital Medical School led to a flurry of reform, but a paper published in the $B M F$ in 1990 showed that doctors from ethnic minorities who had trained in Britain did not progress as fast in their careers as native European doctors. $^{2}$ The authors speculated that this discrimination occurred in shortlisting for senior house officer and registrar posts (rather than in interviews), and today's study supports that speculation.

The shortlisting problem can be countered by not letting those doing the shortlisting have access to the names, ages, and sex of the candidates, and this process should be adopted. But the problem of rooting racial discrimination out of the health service and medicine is a deeper one that needs a broad strategic approach. The Commission for Racial Equality has proposed such a strategy for primary care, ${ }^{11}$ and the NHS Management Executive has issued guidelines on equal opportunities in recruitment and selection procedures. ${ }^{12}$ These policies should be fully supported by doctors and their organisations-because racial discrimination damages both those discriminated against and those doing the discriminating. This damage has been powerfully illustrated in a famous study that depended on deception: John Howard Griffin, a white man, darkened his skin and trudged through the American south. In Black Like Me he writes: "I offer [my account] in all its crudity and rawness. It traces the changes which occur to heart and body when a so called first class citizen is cast on the junkheap of second class citizenship."13

\section{RICHARD SMITH}

Editor

$B M \mathcal{F}$

Esmail A, Everington S. Racial discrimination against doctors from ethnic minorities. $B M 9$ 1993;306:691-2.

2 McKeigue PM, Richards JDM, Richards P. Effects of discrimination by sex and race on the early careers of British medical graduates during 1981-7. BMF 1990;301:961-4.

3 Collier J, Burke A. Racial and sexual discrimination in the selection of students for London medical schools. Med Educ 1986;20:86-90.

Lewis G, Croft-Jeffreys C, David A. Are British psychiatrists racist? Br $\mathcal{F}$ Psychiatry 1990;157: 410-5.

5 King's Fund. The work of the equal opportunities task force 1986-90-a trial report. London: King's Fund, 1991.

6 Kingman S. Black students still underrepresented at UK medical schools. BMF 1992;304:1266.

7 Lowry S, Macpherson G. A blot on the profession. BMF 1988;296:657-8.

7a Persaud R. Home street home. BMF 1993;306:726.

8 Peters DP, Ceci SJ. Peer review practices of psychological journals: the fate of published articles submitted again. Behavioral and Brain Sciences 1982:5:187-95.

Gerber P. Overseas medical practitioners and "racial discrimination." Med f Aust 1991;155:509-12.

10 Moss I. Overseas medical practitioners and "racial discrimination." Med f Aust 1992;156:138.

11 Commission for Racial Equality, Race relations code of practice in primary health care services. London: CRE, 1992 .

2 NHS Management Executive. Equal opportunities in recruitment and selection procedures. London: NHSME, 1991.

13 Griffin JH. Black like me. London: Collins, 1962.

\title{
All the homeless people-where do they all come from?
}

\section{Probably not as many from psychiatric institutions as we think}

The coining of the term "cardboard city" reflects the public consciousness of the visible increase in the number of homeless people on our cities' streets. Because of problems of ascertainment, putting an accurate figure to this total is impossible. Using its restrictive definition of homelessness, the Department of the Environment estimates that the number of homeless families in England has more than doubled over the past decade to 146000 last year. (The housing charity Shelter says that this represents at least 420000 people.)

Many of these people are likely to have serious psychiatric problems. An early study of the Camberwell Reception Centre (now closed) found that one third of the residents were suffering from a severe psychiatric disorder, excluding alcoholism. ${ }^{1}$ Twenty years later, in a survey of men arriving at a Salvation Army hostel a quarter were diagnosed as having schizophrenia. ${ }^{2}$ During the intervening period surveys of homeless people in residential settings have estimated the prevalence of severe mental illness at between $25 \%$ and $45 \%$. While the proportion of mentally ill among homeless people has probably not changed greatly over the past two decades, the absolute number has probably doubled in parallel with the number of homeless people.

The number of occupied psychiatric beds in England has fallen from a peak of 148000 in $1954^{3}$ to about 45000 in 1992. Some commentators have ascribed the rise in the number of homeless mentally ill people to the run down of psychiatric hospitals and have called for a halt to the policy of closure. ${ }^{4}$ But have the erstwhile long stay patients swelled the ranks of homeless people? There are two sources of evidence bearing on this question: one is the psychiatric history of homeless mentally ill people, while the other is follow up studies of long term psychiatric patients discharged into the community.

Only a few of the surveys of homeless mentally ill people have inquired about any history of psychiatric treatment. A study of people using a shelter in Boston found that although 30 of the 68 respondents were suffering from a psychosis, only five had been admitted to hospital for longer than a year in total. ${ }^{5}$ A survey of 124 homeless men using a Salvation Army hostel found that over half were suffering from mental disorders but only seven had been admitted to hospital for longer than a year. ${ }^{2}$ In an experimental study of a case management service for homeless mentally ill people only two out of 94 people referred in a year reported having been admitted to hospital for a year or longer. ${ }^{6}$ During the first year of the London homeless mentally ill initiative 544 homeless people were identified as suffering from severe mental illness. Of these, only three had had a continuous hospital admission lasting more than five years. ${ }^{7}$

The follow up studies of discharged patients have produced complementary evidence. The Team for the Assessment of Psychiatric Services has been evaluating the run down of Friern and Claybury Hospitals in north London. A follow up of the 278 long stay patients discharged between 1985 and 
1988 failed to trace only six people, who were presumed to have become vagrants (three had been vagrants before their admission $\left.^{8}\right)$. Of the 216 patients discharged in 1989-90, none became vagrants during the first year of follow up (J Leff $e t$ al, unpublished study). In a similar study of the closure of Cane Hill Hospital in south London, of 103 patients followed up one year after discharge, none had become homeless. ${ }^{9}$

These two sources of evidence suggest that the discharge of long stay patients from the declining mental hospitals is not the main factor contributing to the increase in the numbers of mentally ill people living on the streets. What other factors might be operating? One of the economic changes that is leading to increasing homelessness is the disappearance of low cost rented accommodation. People suffering from severe psychiatric illnesses are particularly vulnerable to this change because of their high level of unemployment, low earning power, and lack of social support.

Another possible contributory factor is the increasing difficulty in admitting acutely ill patients. The 1983 Mental Health Act, while safeguarding patients' civil rights, has made many mental health professionals reluctant to use its compulsory powers except in extreme cases. Furthermore, psychiatry has been affected by the general reduction in admission beds. Resulting deficiencies in the treatment of acutely ill patients can place intolerable burdens on their families and increase interpersonal friction, which may culminate in patients leaving home abruptly and being unable or unwilling to find alternative forms of shelter.

The fact that severely mentally ill people roam our streets without adequate accommodation and medical care is an inescapable indictment of our society. Instead of assuming that the discharge of patients from psychiatric institutions is to blame we should be studying carefully the pathways that lead mentally ill people into homelessness and destitution. If we are successful in identifying these the opportunities may exist to prevent a situation that is desperately difficult to cure.

MRC Social and Community Psychiatry Unit,

JULIAN LEFF Director

Institute of Psychiatry,

London SE5 8HF

1 Tidmarsh D, Wood S. Psychiatric aspects of destitution. In: Wing JK, Hailey AM, eds. Evaluating a community psychiatric service. Oxford: Oxford University Press, 1972:327-40

2 Timms PW, Fry AH. Homelessness and mental illness. Health Trends, 1989-21:70-1.

3 Tooth G, Brooke E. Trends in mental hospital population and their effect on future planning. Lancet 1961;: 710 -3.

4 Weller MPI. Mental illness-who cares? Nature 1989:339:249-52.

5 Bassuk EL, Rubin L, Lauriat A. Is homelessness a mental health problem? Am $\mathcal{J}$ Psychiatry 1984;141:1546-50.

6 Brent-Smith H, Dean R. Plugging the gaps. London: Lewisham and North Southwark Health Authority, 1990.

7 Craig TKJ, Timms PW. Out of the wards and onto the streets? Deinstitutionalization and homelessness in Britain. Journal of Mental Health 1992;1:265-75.

8 Dayson D. Crime, vagrancy, death and readmission of the long-term mentally ill during their first year of local reprovision. Br $\mathcal{F}$ Psychiatry 1993;suppl 19:43-7.

9 Pickard L, Proudfoot R, Wolfson P. The closure of Cane Hill Hospizal: repon of the Cane Hill evaluation team. London: Research and Development for Psychiatry, 1991.

\section{The Journal of Medical Screening}

\section{A new journal aims to focus a scattered subject}

When so many diseases cannot be cured, medical screening has intuitive appeal. It offers excellent opportunities for preventing disease, but currently the subject lacks an intellectual and practical focus. A recent British report showed that potentially effective screening tests have been poorly implemented, while other tests have been introduced into practice without adequate evidence of benefit. ${ }^{1}$ The same story is seen the world over, and there are considerable variations among countries in the ways in which screening tests are introduced and how they are applied. Understandably, health workers and the public are confused. As a contribution to raising the intellectual rigour of the subject and improving professional and public understanding the BMJ Publishing Group is to launch the fournal of Medical Screening next January.

At the outset potential screening tests need to be rigorously evaluated. It is not enough to show that a screening test detects disease early, or even that it will probably save some lives. Before a screening test is introduced into practice the efficacy of the test in detecting disease and the effectiveness of early intervention in preventing death or disability must first be quantified. These benefits must be set against the costs, measured in both financial and medical terms, so that a judgment can be made on whether the benefits justify the cost. Once a screening programme has been introduced, continued research is needed to monitor and improve screening performance.

The new journal will encourage the publication of the essential information on screening performance and costs so that rational decisions can be made on screening practice. It will include papers on all aspects of proposed new screening tests and on improvements to existing tests together with regular critical reviews. Such papers are widely dispersed at present, in specialist clinical, radiological, pathological, and epidemiological journals. The fournal of Medical Screening will help to reduce this diffusion and concentrate the subject without sacrificing its multidisciplinary nature. The philosophy of the journal is that screening should be about the prevention of disability and disease, not simply the early detection of disease as an end in itself.

In addition to advancing the science of screening the journal will guide its implementation. Screening services are often fragmented, and the public may not have equal access to particular screening programmes. The journal will encourage discussion on these issues. The psychological, managerial, economic, and social aspects of screening will therefore be considered. The journal will ask such questions as where screening should be carried out, who should do it, and how often screening examinations should be repeated. The difficult ethical issues that are often raised by screening programmes will also be grasped.

The Fournal of Medical Screening aims to be international and multidisciplinary, and the editorial board reflects these aims. A call for papers for the new journal appears opposite p 721, and we welcome contributions now. The journal will be launched at a major conference to be held in London next January.

Wolfson Institute of Preventive Medicine, St Bartholomew's Hospital Medical College, London EC1M 6BQ

CHOLAS WALD Professor, and editor of fournal of Medical Screening

$B M \mathcal{F}$

RICHARD SMITH Editor

1 Advisory Council on Science and Technology. $A$ report on medical research and health. London: HMSO, 1993. 